\title{
Enhanced Prostacyclin Synthesis in Endothelial Cells by Retrovirus-mediated Transfer of Prostaglandin H Synthase cDNA
}

\author{
Xiao-Ming Xu, Kazuteru Ohashi, Sudershan K. Sanduja, Ke-He Ruan, Lee-Ho Wang, and Kenneth K. Wu \\ Vascular Biology Research Center, Department of Internal Medicine, Division of \\ Hematology, University of Texas Health Science Center at Houston, Texas 77030
}

\begin{abstract}
A retroviral vector (BAG) was used to transfer human prostaglandin $\mathrm{H}$ synthase (PGHS-1) gene into a human endothelial cell line for enhancement of $\mathbf{P G I}_{2}$ synthesis. Cells infected with BAG containing PGHS-1 cDNA in the sense orientation relative to the retroviral promoter (PGHS(S)) expressed a 30-fold increase in mRNA but, due to a reading frame shift, did not show an increase in PGHS protein or in $\mathbf{P G I}_{2}$ synthesis, while those with PGHS-1 in reverse orientation relative to the viral promoter (PGHS(R)), produced a $>10$-fold increase in PGHS mRNA over the control $(169 \pm 22$ vs $14.8 \pm 1.2 \mathrm{amol} / \mu \mathrm{g}$ RNA) with a concordant increase in PGHS protein (5.82 \pm 1.07 vs 0.23 $\pm 0.04 \mathrm{ng} / \mathrm{mg}$ protein) and enzyme activity. Primer extension analysis of PGHS( $R$ ) revealed two transcription start sites located in the SV40 late promoter region adjacent to PGHS-1 cDNA. PGHS(R) cells produced a high basal PGI level which was increased by several-fold in response to stimulation by ionophore, arachidonic acid, and thrombin. Kinetic analysis revealed the $P G I_{2}$ synthetic rate to be $14 \mathrm{ng} / \mathrm{min}^{-1}$ per

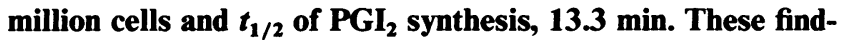
ings indicate that transfer of PGHS-1 gene into vascular cells enhances $P \mathrm{I}_{2}$ synthesis and may be a useful strategy for restoring thromboprotective property of damaged blood vessels. ( $J$. Clin. Invest. 1993. 91:1843-1849.) Key words: prostaglandin H synthase • prostacyclin • gene transfer • vascular endothelial cells $\bullet$ thrombosis
\end{abstract}

\section{Introduction}

Prostaglandin H synthase (PGHS, ${ }^{1}$ cyclooxygenase, EC1.14 .99 .1 ) is a key enzyme in controlling the extent of prostanoid biosynthesis (for reviews, see 1-3). It possesses two enzymatic activities: cyclooxygenase activity which catalyzes the conversion of $\mathrm{AA}$ to $\mathrm{PGG}_{2}$ and peroxidase activity, the conversion of $\mathrm{PGG}_{2}$ to $\mathrm{PGH}_{2}$. $\mathrm{PGH}_{2}$ is the common precursor for a number

Address correspondence to Dr. Kenneth $\mathrm{K}$. Wu, University of Texas Medical School, 6431 Fannin, Houston, TX 77030.

Received for publication 28 August 1992 and in revised form 12 January 1993.

1. Abbreviations used in this paper: LTR, long terminal repeat; PGHS, prostaglandin $\mathbf{H}$ synthase.

J. Clin. Invest.

(c) The American Society for Clinical Investigation, Inc. $0021-9738 / 93 / 04 / 1843 / 07 \quad \$ 2.00$

Volume 91, April 1993, 1843-1849 of biologically important prostanoids, i.e., prostacyclin ( $\mathrm{PGI}_{2}$ ), thromboxane $\mathrm{A}_{2}, \mathrm{PGE}_{2}, \mathrm{PGD}_{2}$, and $\mathrm{PGF}_{2 \alpha}$. PGHS is distributed in most mammalian tissues in low abundance. It is autoinactivated during catalysis $(4,5)$ which severely curtailed the prostanoid synthesis. At least two forms of PGHS have been identified and their genes have been cloned. PGHS originally cloned from ram seminal vesicles (designated PGHS-1) and subsequently from mouse tissues, human endothelial cells, and platelets, is well conserved and considered to be constitutive (6-10) while the second type of PGHS (PGHS-2) cloned from chicken embryonic fibroblasts and mouse $3 \mathrm{~T} 3$ fibroblasts is highly inducible (11-13).

Cultured human endothelial cells have been used as a cell model for studying the regulation of PGHS expression and the relation of PGHS level to $\mathrm{PGI}_{2}$ biosynthesis. Several laboratories including ours have shown that the extent of $\mathrm{PGI}_{2}$ biosynthesis is governed by the level of PGHS-1 which depends on the balance between de novo synthesis and autoinactivation of PGHS (14-17). However, the exact relationship between PGHS expression and the capacity for $\mathrm{PGI}_{2}$ synthesis has not been established by quantitative analysis because of technical limitations for measuring low levels of PGHS mRNA and protein. In this study, we used retrovirus-mediated transfer of PGHS-1 cDNA to enhance PGHS expression in an endothelial cell line EA.hy926. The PGHS mRNA level in infected cells was enhanced over that in uninfected cells by one to two orders of magnitude with a concordant increase in PGHS protein level and enzyme activity. These cells produced a large quantity of $\mathrm{PGI}_{2}$ in response to arachidonic acid, calcium ionophore A23187, and thrombin stimulation. The rate of $\mathrm{PGI}_{2}$ synthesis was determined to be $14 \mathrm{ng} / \mathrm{min}^{-1}$ per million cells and $t_{1 / 2}$ of $\mathrm{PGI}_{2}$ synthesis was $13.3 \mathrm{~min}$.

\section{Methods}

Retroviral vectors. The BAG vector, kindly supplied by Connie Cepko, Harvard Medical School, was constructed as previously described (18). It contains a 3-kb BamHI fragment encoding Escherichia coli $\beta$-galactosidase gene (Fig. 1). To prepare retroviral vectors for PGHS gene transfer, the $\beta$-gal fragment was replaced with a 2.5 -kb BamHI fragment which includes the entire coding region and the polyadenylation signal of a human endothelial cell PGHS-1 cDNA cloned in our laboratory. When compared to a published human PGHS-1 cDNA (19), our clone lacked the first 42 bases from the ATG site, coding for part of the signal peptide. An oligonucleotide was inserted into this region to produce a signal peptide sequence of MSRSLLLRFLLLLLLIPLLSLPVLL, which differs from that reported by Yokoyama and Tanabe (19): MSRSLLLRFLLLLLLLPPLPVLL in several residues denoted by the underlined amino acids. Preliminary results on expression of our PGHS-1 cDNA in COS-1 cells indicated that this difference 

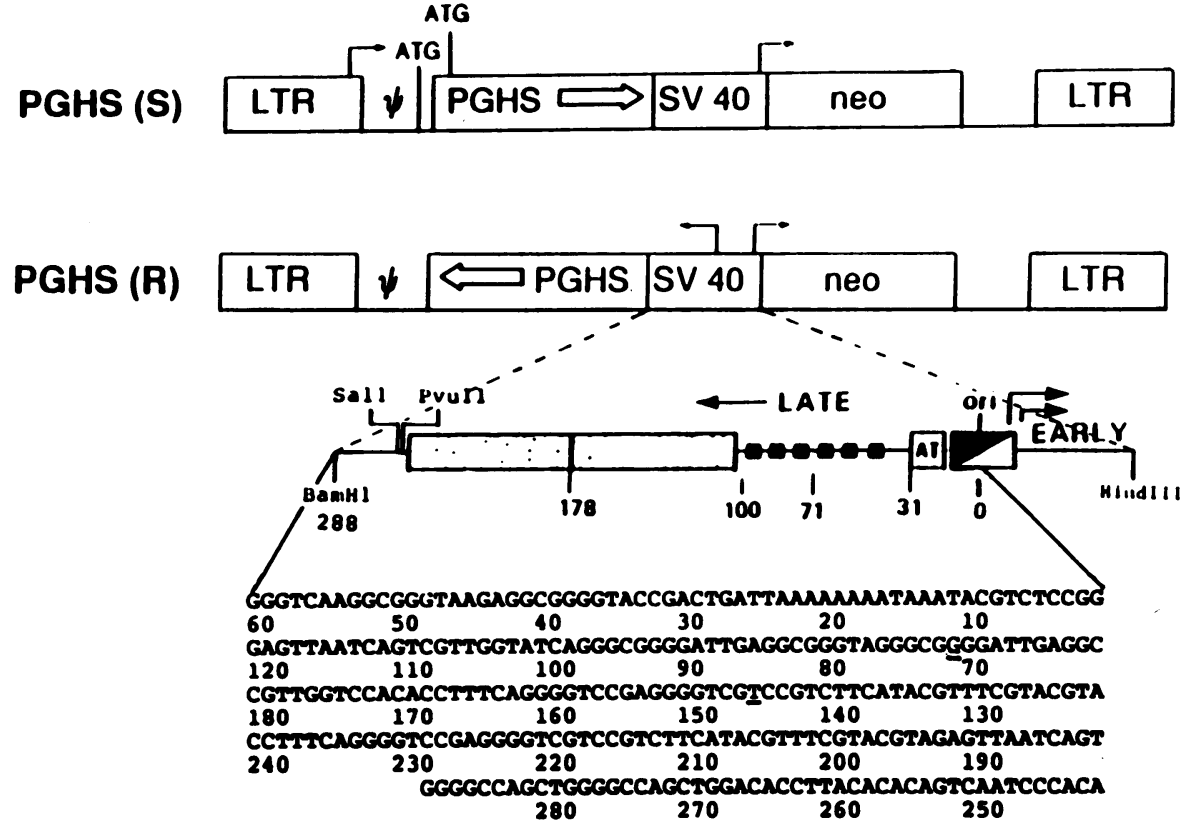

Figure 1. Retroviral vectors. The arrows above LTR and SV40 indicate the direction of transcription. The arrows within the PGHS box indicate the direction of coding strand. PGHS(S) denotes the insertion of PGHS- 1 in sense orientation relative to the retroviral promoter and PGHS(R), reverse orientation relative to the retroviral promoter. $L T R$, retroviral long terminal repeat; $\psi$, viral sequence essential for packaging; $A T G$, translation start codon; $\beta$-gal, $\beta$-galactosidase $c D N A, S V 40$, simian virus 40 promoter and enhancer; $n e o$, bacterial neomycin phosphotransferase cDNA; PGHS, human PGHS-1 cDNA. The cloning site, BamHI, in the BAG is also shown The nucleotide sequence of the SV40 late promoter was numbered according to Fromm and Berg (33). The two underlined bases at nucleotides 71 and 145 denote transcription start sites for PGHS mRNA. These sequence data are available from Genbank under accession number V01380. in the signal peptide had no effect on the cellular location or the expression of PGHS activity (Ren, Y., and R. J. Kulmacz, personal communication). Colonies of BAG vectors containing PGHS-1 cDNA in the same transcription orientation as the 5'-long terminal repeat (LTR), i.e., the sense orientation (designated as PGHS(S)), and in the reverse orientation (designated as PGHS(R)), were selected by growth in medium containing G418. The orientation of the PGHS-1 cDNA insert was determined by restriction enzyme mapping.

Production of replication-defective retrovirus. BAG, PGHS(S), and PGHS(R) were introduced into an amphotropic packaging cell line, భCRIP (20), kindly supplied by Richard Mulligan at Massachusetts Institute of Technology. After selection, G418-resistant colonies were isolated. The virus titer used to infect cells was $10^{4}-10^{6} \mathrm{CFU} / \mathrm{ml}$.

Cell culture. The $\psi$ CRIP packaging cell line and NIH 3 T 3 cells were grown in DMEM supplemented with $10 \%$ FCS, $100 \mathrm{U} / \mathrm{ml}$ penicillin, $100 \mu \mathrm{g} / \mathrm{ml}$ streptomycin, and $4 \mathrm{mM} \mathrm{L}$-glutamine. The human endothelial hybrid cell line, EA.hy926, provided by Cora-Jean Edgell at the University of North Carolina, Chapel Hill, was cultured as previously described $(21,22)$. These hybrid cells were clonally isolated and passaged numerous times without apparent changes in their endothelial morphology or functional characteristics. They were grown in DMEM supplemented with $10 \%$ heat-inactivated FBS, penicillin $(100 \mathrm{U} / \mathrm{ml})$, streptomycin $(100 \mu \mathrm{g} / \mathrm{ml}$ ), and HAT (hypoxanthine $100 \mu \mathrm{M}$, aminopterin $0.4 \mu \mathrm{M}$, and thymidine $16 \mu \mathrm{M}$ ).

Infection of endothelial cells. Monolayers of EA.hy926 cells in T-25 flasks were incubated at $37^{\circ} \mathrm{C}$ in a $5 \% \mathrm{CO}_{2}$ incubator for $3 \mathrm{~d}$ with $9 \mathrm{ml}$ of culture medium containing $8 \mu \mathrm{g} / \mathrm{ml}$ polybrene and $3 \mathrm{ml}$ of replication-defective retroviral suspension. The cells were washed and incubated with fresh media containing $100 \mu \mathrm{g} / \mathrm{ml}$ of G418 every third day. The cells reached confluency 2 wk after infection and all the BAG-infected cells expressed $\beta$-galactosidase (detected by staining with $X$-gal). The infected cells had a similar doubling time $(\sim 48 \mathrm{~h})$ as the uninfected cells and reached confluency 5-6 d after subculture. They have been subcultivated for $>10$ passages with no change in their morphological characteristics or growth.

Northern blot analysis. RNA was prepared from infected and uninfected cells by a procedure previously described (23). Poly A(+) RNA was prepared from the total RNA by oligo-dT column chromatography. Gel electrophoresis, gel transfer, and hybridization with a 2.1-kb human PGHS cDNA were performed as previously described (23).

Quantitative $P C R$. This assay was based on procedures previously described (24-26). For assay of PGHS-1 mRNA, we used a fragment of human PGH synthase genomic DNA (gDNA) as the template for generating gRNA to serve as an internal standard. This template was $320 \mathrm{bp}$ in size, covering all of exon 6 , a small fragment of exon 7 , and the 110-bp sequence between exons 6 and 7. The sequences of 5'- and 3'-flanking oligonucleotide primers used for PCR amplification were: 5'-GGAAGAAGCAGTTGCCAGATGCCCAGCTCC-3' (designated W-16) and 5'-TTGTCTCCATAAATGTGGCCGAGGTCTACC-3' (designated W-17). Both primers were synthesized by Genosys Biotech, Houston, Texas. The detailed assay procedure was identical to that already described (26).

Primer extension analysis. The transcription initiation sites of PGHS(R) constructs were determined by primer extension using two synthetic antisense oligonucleotide primers: $(a)$ a 24 -mer (5'-CAACAGGGATTCACTGGCGTGGGC-3'), the 5'-terminus of which is corresponding to the nucleotide residue 110 downstream from the ATG site of PGHS cDNA (designated W-1) and (b) a 20-mer (5'AGGAGCGGAATTCCCAGCAA-3', designated W-76) the 5'-terminus of which is corresponding to the residue 54 downstream from the ATG site. Total cellular RNA ( $120 \mu \mathrm{g}$ ) isolated from PGHS(R) cells was used as the template for primer extension which was performed according to the procedure described (27). Using W-1 as the primer, we observed a single band of 258 nucleotides in length and with W-76 as the primer, we noted a major band of 278 and a minor band of 198 nucleotides in length.

Prostacyclin synthesis. Monolayers of cells were washed twice with culture medium and were incubated with various stimulants for $1 \mathrm{~h}$ at $37^{\circ} \mathrm{C}$ before the supernatant liquid was removed and assayed for $6 \mathrm{KPGF}_{1 \alpha}$ by specific radioimmunoassay as described previously (28).

Chromatographic separation of AA metabolites by HPLC. Monolayers of infected or control cells were washed and incubated in fresh medium (without serum) containing $10 \mu \mathrm{M}$ of $\left[1-{ }^{14} \mathrm{C}\right] \mathrm{AA}$ at $37^{\circ} \mathrm{C}$ for $10 \mathrm{~min}$. Eicosanoids in the conditioned medium were extracted using a 
Sep-Pak cartridge (Waters Associates, Millipore Corp., Milford, MA) as described by Eling et al. (29). Recovery of eicosanoids in this extraction procedure was $\sim 95 \%$. Eicosanoids were separated and analyzed by reverse-phase HPLC as previously described (30).

Enzyme immunoassay for PGHS protein levels. The assay used polystyrene beads $(3.2 \mathrm{~mm}$ in diameter; Precision Plastic Ball Co. Chicago, IL) coated with rabbit polyclonal anti-PGHS antibody or preimmune IgG. Monolayers of cultured cells were lysed and the protein was solubilized with $1 \% n$-octyl $\beta$-D-glucopyranoside. Samples and standards were incubated with the antibody-coated polystyrene beads for $3 \mathrm{~h}$ at room temperature and then overnight at $4^{\circ} \mathrm{C}$. The beads were washed and then incubated at room temperature for $4 \mathrm{~h}$ with antiPGHS $F(a b)_{2}$ fragment conjugated to $\beta$-D-galactosidase. After washing, a fluorescent substrate (4-methyl umbelliferyl $\beta$-D-galactoside) was added and incubation continued for $90 \mathrm{~min}$. The reaction was stopped and the fluorescence intensity ( $\lambda$ ex $=360 \mathrm{~nm} ; \lambda \mathrm{em}=450$ $\mathrm{nm}$ ) was determined. A calibration curve derived from ovine PGHS standards was plotted on a logarithmic scale and a least-squares fit determined by linear regression. The correlation coefficient was $>0.995$. The detection limit of the assay was $50 \mathrm{pg}$ of PGHS protein.

Determination of $P G I_{2}$ synthetic rate. PGHS(R) cells and parental EA.hy926 cells were washed with fresh medium and incubated in fresh media containing $10 \mu \mathrm{M}$ AA at $37^{\circ} \mathrm{C}$. At a time period from 0 to 180 min after addition of AA, a small aliquot of medium was removed for 6
keto-PGF ${ }_{1 \alpha}$ assay. Kinetic data of $\mathrm{PGI}_{2}$ production was fit to a single exponential function by the Marquardt-Levenberg algorithm of nonlinear regression. The maximal production of $\mathrm{PGI}_{2}$ expressed as $6 \mathrm{KPGF}_{1 \alpha^{\max }}$, and the rate constant, $\mathrm{K}_{d}$, were obtained from this regression analysis. $\mathrm{PGI}_{2}$ synthetic rate and $t_{1 / 2}$ of synthesis were derived from rate constant.

\section{Results}

PGHS-1 mRNA in control cells was undetectable by Northern blot analysis. By contrast, the mRNA in PGHS(S) and PGHS(R) cells was present as a distinct band of $7.6 \mathrm{~kb}$ and 3.3 $\mathrm{kb}$ in length, respectively (Fig. $2 A$ ). The mRNA levels were quantified by competitive PCR assay (Fig. 2, $B$ and $C$ ). The parental EA.926 cells contained 14.8 \pm 1.2 amol of PGHS mRNA/ $\mu \mathrm{g}$ of total cellular RNA. The mRNA levels in PGHS(S) and PGHS(R) cells were 33-fold and 11-fold higher than that of uninfected cells, respectively (Fig. $3 a$ ). To determine whether PGHS-1 mRNA in the infected cells was properly translated into PGHS-1 enzyme, we measured PGHS-1 protein levels by a fluorimetric enzyme immunoassay. To our surprise, the enzyme level expressed in PGHS(S) cells was not

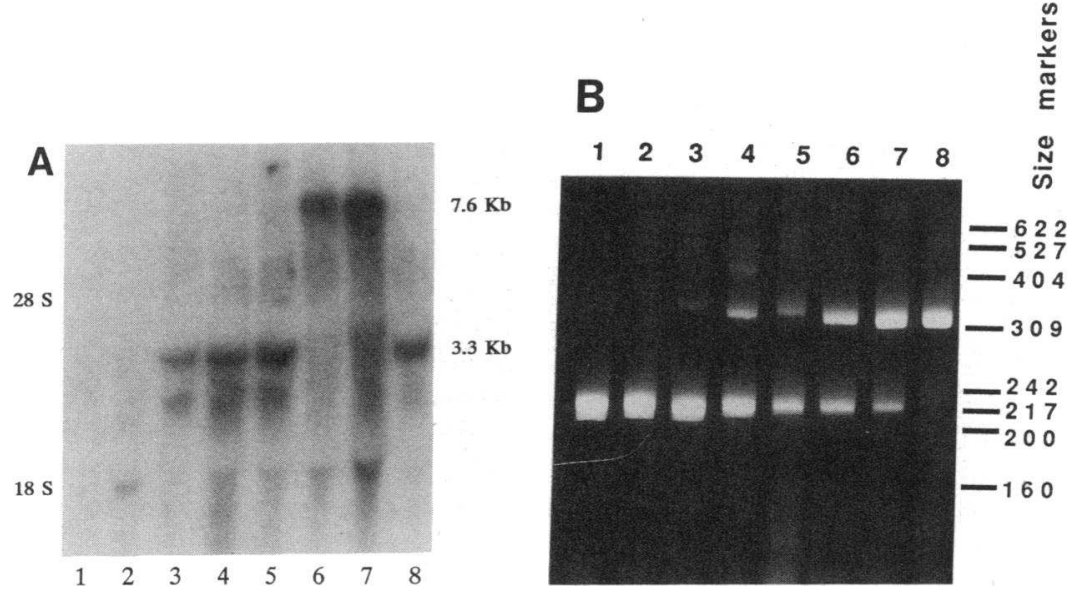

C

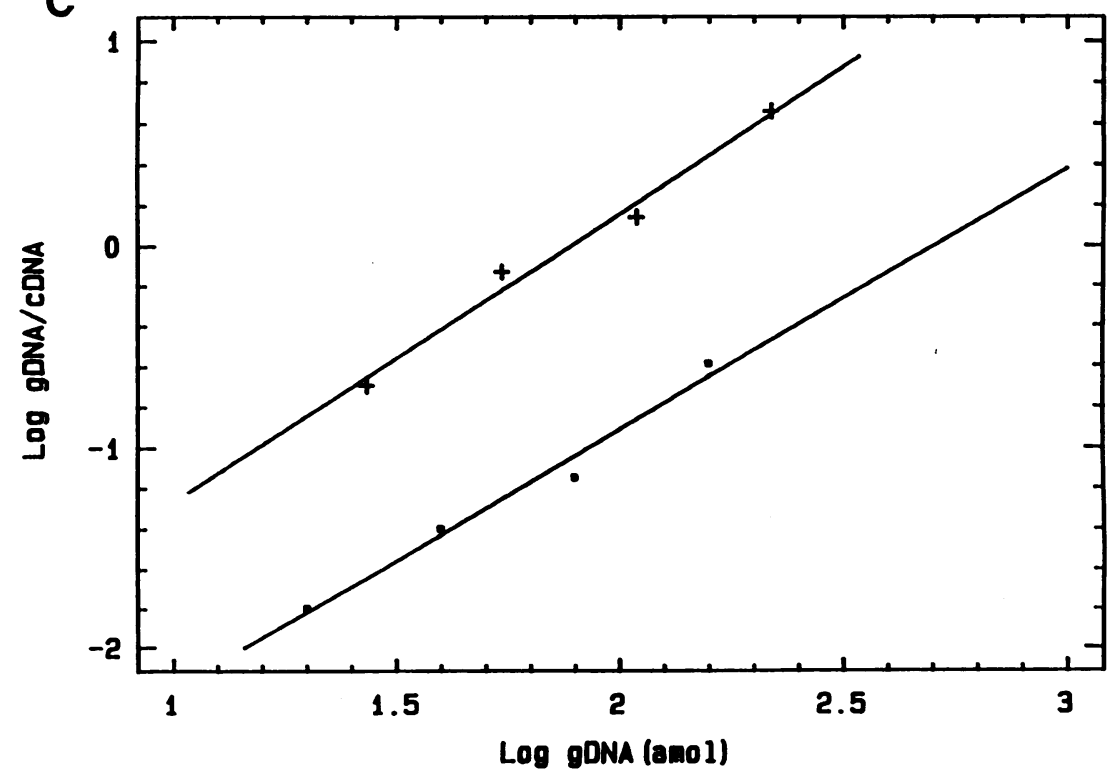

Figure 2. $(A)$ Northern blot analysis of PGHS mRNA in uninfected EA.hy926 (lanes 1 and 2), PGHS(R) cells (lanes 3-5 and 8; lane 5 was stimulated with $50 \mathrm{nM}$ of PMA for $4 \mathrm{~h}$ ) and PGHS(S) cells (lanes 6 and 7). The ribosomal 28 $\mathrm{S}$ and $18 \mathrm{~S}$ markers are shown on the left-hand side and the mRNA sizes are marked on the right-hand side. ( $B$ and $C$ ) A representative assay of PGHS-1 mRNA levels in PGHS(S) and PGHS(R) cells by competitive PCR. Detailed methodology is described in Methods. $B$ shows the result of gel electrophoresis which separates the PCR products into two distinct bands, 320-bp band being the gDNA fragment and 210-bp band the cDNA fragment. Lanes 1-4 donate the assay of mRNA level in PGHS(S) cells wherein an increasing concentration of the gRNA standard (20, 40,80 , and $160 \mathrm{amol}$ ) and a fixed quantity of total cellular RNA $(0.5 \mu \mathrm{g})$ were added to each of the four assay tubes. Lanes 5-8 denote the assay for PGHS( $R$ ) cell mRNA level. The experimental condition was identical except that $1 \mu \mathrm{g}$ of total RNA was added. Each band was excised and radioactivity was determined. The ratio of gDNA/ cDNA radioactivity was plotted against the gDNA concentration in a logarithmic scale shown in $C$. (+) denotes PGHS(R) and ( $($ ) PGHS(S). The concentration of mRNA was computed from the linear regression. 

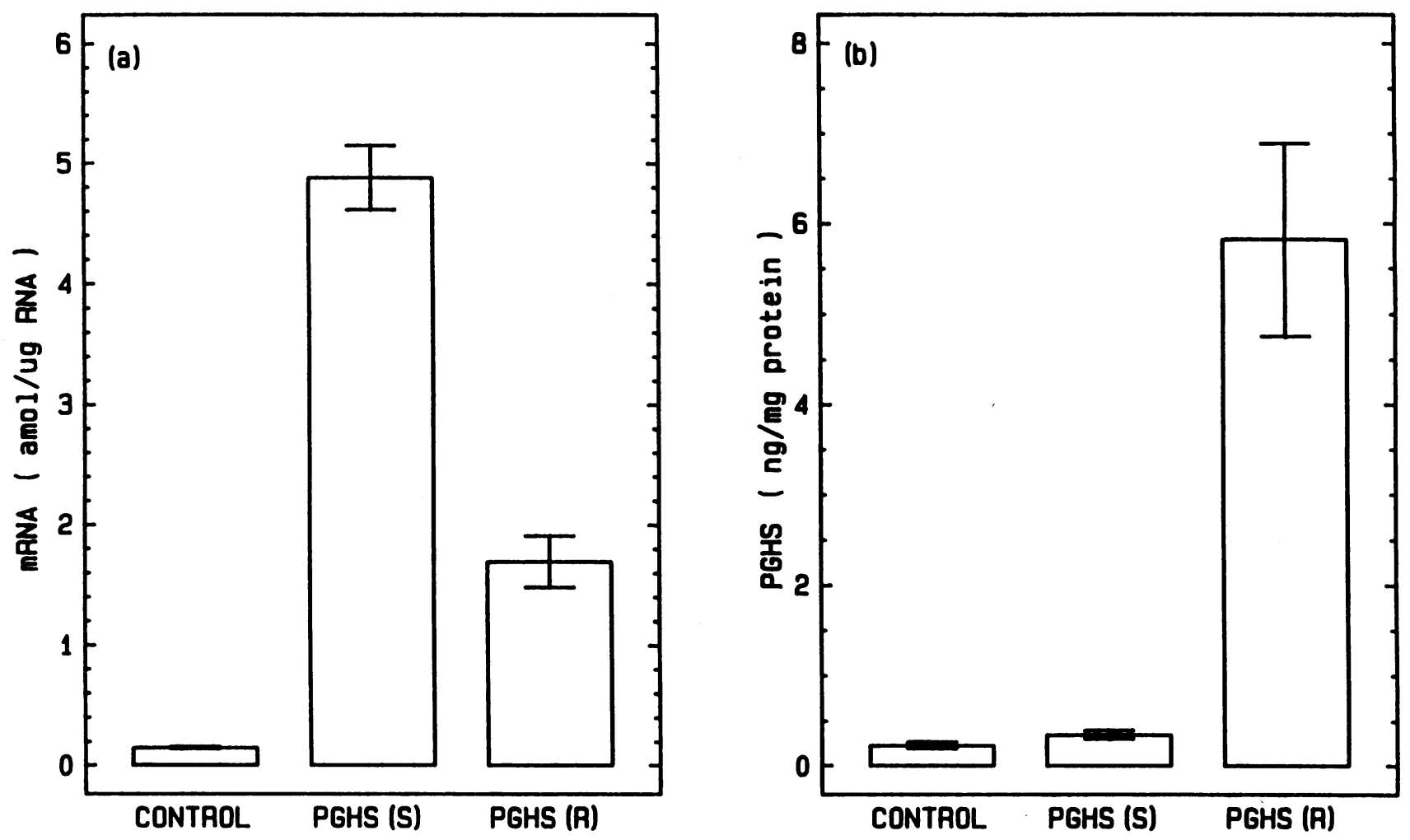

Figure 3. Comparison of PGHS-1 mRNA $(a)$ and protein levels $(b)$ in uninfected, PGHS(S), and PGHS(R) endothelial cells. Each bar represents mean value \pm standard deviation from three separate experiments.

significantly higher than that present in uninfected cells (Fig. 3 $b)$. On the other hand, the enzyme level expressed in PGHS(R) cells was $\sim 25$-fold higher than that in the control cells. These results were supported by HPLC data shown in Fig. 4. PGHS(S) cells produced very small amounts of cyclooxygenase products equivalent to those of control cells when they were treated with $\left[1-{ }^{14} \mathrm{C}\right.$ ] AA while PGHS(R) cells generated a large quantity of $\mathrm{PGI}_{2}$ and $\mathrm{PGE}_{2}$. The PGHS-1 enzyme activity estimated from the HPLC analysis was in accord with that of protein expression in these cells.

Despite expression of an increased PGHS-1 mRNA level by the insertion of PGHS-1 cDNA into the BAG vector in a sense orientation relative to retroviral LTR promoter, expression of PGHS protein and enzyme activity were not concordantly enhanced. This discrepancy led us to suspect that there might be a shift in the reading frame. We analyzed the nucleotide sequence of the fragment between the retroviral gag ATG originally placed in the BAG vector as the translation start codon for $\beta$-galactosidase and the inherent start codon of PGHS cDNA inserted into the BAG in place of $\beta$-galactosidase (Fig. 1). We found that PGHS ATG was $1 \mathrm{bp}$ out of frame from the gag ATG. Failure of a proper protein translation because of reading frame shift may be due to the preferential use of the gag ATG as the translation start codon.

Judging from the length of PGHS-1 mRNA (3.3 kb) expressed in PGHS(R) cells, we postulated that the transcription initiation site was localized within the SV40 promoter region which was originally inserted in the BAG vector for promoting the expression of the neo ${ }^{R}$ gene (Fig. 1). To determine this, we carried out primer extension experiments to define the potential transcription start sites. Primer extension analysis revealed two start sites mapped to the late SV40 promoter region close to the origin of DNA replication (Fig. 1). To define the exact transcription initiation sites, we sequenced this region with two synthetic primers, designated W-1 and W-76 (see Methods for the sequences). The sequence we obtained matched that reported in the GenBank for the SV40 late promoter region (accession number V01380) (Fig. 1). Based on the length of the primer extension products, we mapped the transcription start sites to nucleotide residue 71 and residue 145 .

The extent of $\mathrm{PGI}_{2}$ synthesis by PGHS(R) cells is shown in Table I. These cells produced a high basal level of $\mathrm{PGI}_{2}$ when compared to control and PGHS(S) cells. They were capable of responding to stimulation by thrombin, ionophore $A 23187$, and $\mathrm{AA}$ which increased $\mathrm{PGI}_{2}$ formation by three-, eight-, and fivefold over the basal $\mathrm{PGI}_{2}$ level, respectively (Table I). The $\mathrm{PGI}_{2}$ levels produced by $\mathrm{PGHS}(\mathrm{R})$ cells in response to stimulation were at least 20 -fold higher than those produced by PGHS(S) or parental cells under an identical stimulatory condition. Multiple passages of PGHS(R) cells in culture did not have an apparent effect on their $\mathrm{PGI}_{2}$-generating capacity. Cells that had undergone seven passages in culture produced a similar quantity of $\mathrm{PGI}_{2}$ as those which were freshly infected with PGHS(R) vectors before passage (PO) (Table I). $\mathrm{PGI}_{2}$ synthetic capacity remained stable after 10 passages in culture (data not shown).

$\mathrm{PGI}_{2}$ synthesis by cultured endothelial cells or vascular tissues is limited because of "suicidal" inactivation of PGHS and 

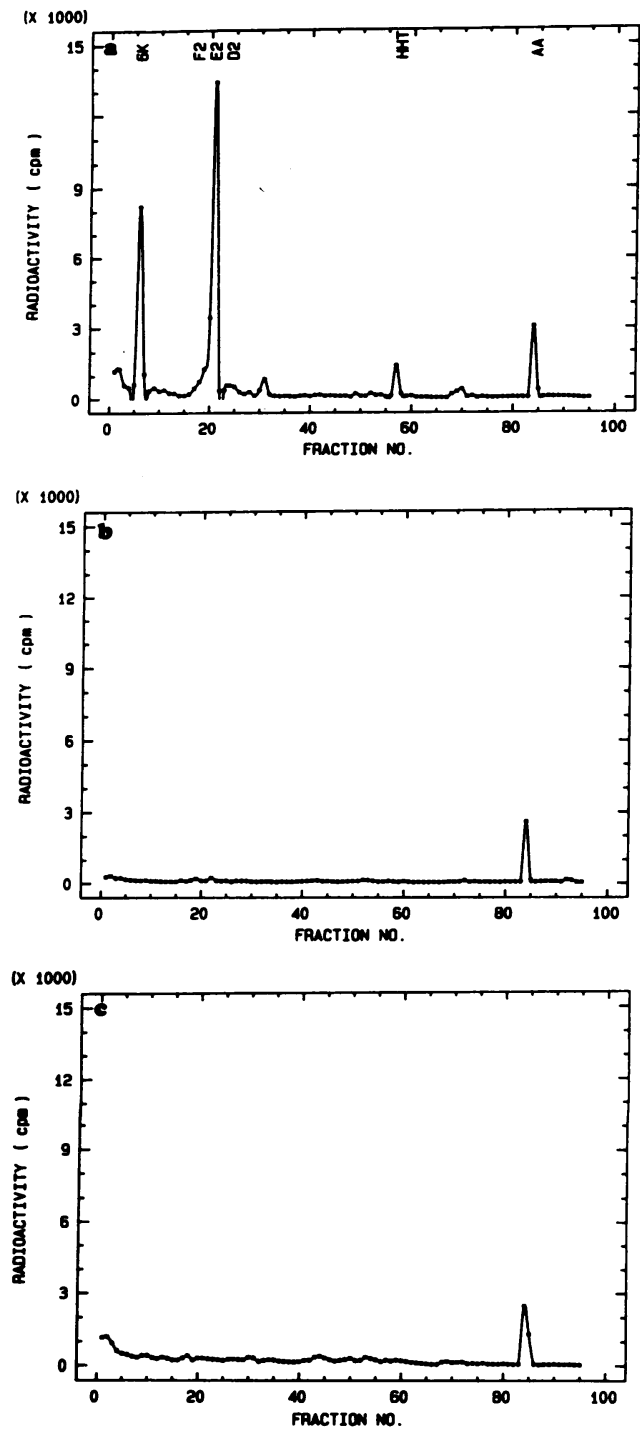

Figure 4. Analysis of arachidonate metabolites by reverse-phase HPLC. The details were described in Methods. (a) PGHS(R) cells; (b) PGHS (S) cells; and (c) uninfected EA.hy926 cells. Coelution of radiolabeled authentic eicosanoids is shown. $6 \mathrm{~K}$ denotes 6 keto-prostaglandin $\mathrm{F}_{1 \alpha} ; \mathrm{F}_{2 \alpha}, \mathrm{PGF}_{2 \alpha} ; \mathrm{E}_{2}, \mathrm{PGE}_{2} ; \mathrm{D}_{2}, \mathrm{PGD}_{2} ; \mathrm{HHT}$, 12-hydroxy5,8,10-heptadecatrienoic acid; and AA, arachidonic acid.

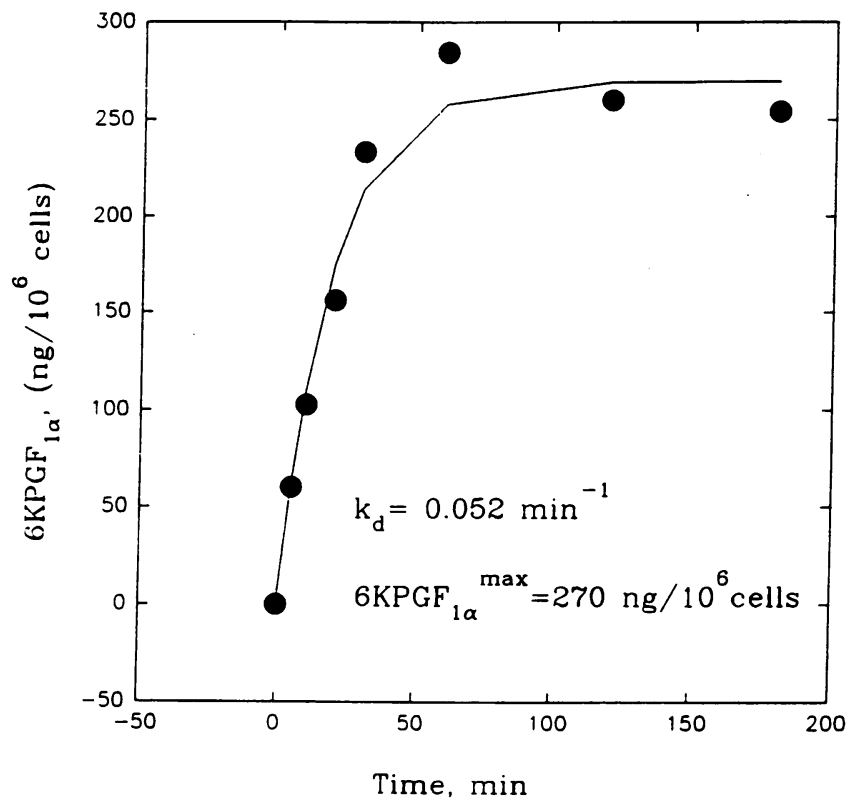

Figure 5. Kinetics of $\mathrm{PGI}_{2}$ synthesis in PGHS(R) cells. Each dark dot represents the mean value of two experiments. The data were fit to a one-exponential regression. Similar experiments were performed in uninfected cells. Due to low $\mathrm{PGI}_{2}$ formation, fitting of the curve was difficult and hence the synthetic and decay rates were impossible to determine (data not shown).

PGI synthase during catalysis $(4,5,31)$. $\mathrm{PGI}_{2}$ synthetic rate has been difficult to quantify because of low levels of $\mathrm{PGI}_{2}$ productions. Since this stably infected endothelial cell line produced a high level of $\mathrm{PGI}_{2}$, we thought it might be suitable for accurate determination of $\mathrm{PGI}_{2}$ synthetic rate. We treated PGHS(R) cells with AA $(10 \mu \mathrm{M})$ at $37^{\circ} \mathrm{C}$ and at indicated time points, a small aliquot of the cultured medium was collected and its 6-keto-PGF ${ }_{1 \alpha}$ content was measured by RIA. The results are shown in Fig. 5 . The time course of $\mathrm{PGI}_{2}$ synthesis in PGHS(R) cells fits a single-exponential regression. $\mathrm{PGI}_{2}$ synthesis reached a plateau after the cells had been treated with the agonists for $30 \mathrm{~min}$. The maximal production of $\mathrm{PGI}_{2}$ obtained by nonlinear regression was $270 \mathrm{ng} / 10^{6}$ cells and the rate constant was $0.052 \mathrm{~min}^{-1}$ (Fig. 5). $\mathrm{PGI}_{2}$ synthetic rate was 14 $\mathrm{ng} / \mathrm{min}^{-1}$ per $10^{6}$ cells and the $t_{1 / 2}$ of $\mathrm{PGI}_{2}$ synthesis was 13.3

Table I. Responses of Retrovirus-infected and Control Cells to Stimulation by Physiological Agonists

\begin{tabular}{|c|c|c|c|c|c|}
\hline \multirow[b]{3}{*}{ Experiment } & \multicolumn{5}{|c|}{$6 \mathrm{KPGF}_{1 \alpha}$ concentration } \\
\hline & \multicolumn{2}{|c|}{ PGHS(R) } & \multicolumn{2}{|c|}{ PGHS(S) } & \multirow[b]{2}{*}{ Control } \\
\hline & PO & P7 & PO & P7 & \\
\hline \multicolumn{6}{|c|}{$n g / m l$} \\
\hline Basal & $5.75 \pm 0.22$ & $4.00 \pm 2.60$ & $0.22 \pm 0.01$ & $0.16 \pm 0.05$ & $0.12 \pm 0.01$ \\
\hline A23187 & $46.79 \pm 7.03$ & $76.08 \pm 0.10$ & $0.57 \pm 0.02$ & $0.18 \pm 0.01$ & $0.29 \pm 0.03$ \\
\hline Thrombin & $17.89 \pm 0.39$ & $15.97 \pm 0.67$ & $0.39 \pm 0.01$ & $0.37 \pm 0.01$ & $0.19 \pm 0.10$ \\
\hline Arachidonate & $26.70 \pm 0.75$ & ND & $2.34 \pm 0.05$ & ND & $0.32 \pm 0.05$ \\
\hline
\end{tabular}

The $6 \mathrm{KPGF}_{1 \alpha}$ content (mean $\pm \mathrm{SD}, n=3$ ) in the cultured medium from primary (P0) and passage 7 (P7) PGHS(R) and PGHS(S) cells and from control cells. Cells $\left(2 \times 10^{5}\right.$ cells/well) were incubated with $1 \mathrm{ml}$ of medium containing ionophore A23187 $(10 \mu \mathrm{M})$, thrombin $(2 \mathrm{U} / \mathrm{ml})$, and arachidonate $(10 \mu \mathrm{M})$ at $37^{\circ}$ for $1 \mathrm{~h}$, and the $6 \mathrm{KPGF}_{1 \alpha}$ content in the cultured medium was assayed. ND, not done. 
min. The time course for $\mathrm{PGI}_{2}$ production in the parental cells was bell-shaped: $\mathrm{PGI}_{2}$ production reached a maximal level 1030 min after AA treatment and declined thereafter (data not shown). The level produced at each time was at least one order of magnitude lower than that produced by PGHS(R) cells and was highly variable. These factors render the determination of rate constant and consequently synthetic rate and $t_{1 / 2}$ of $\mathrm{PGI}_{2}$ synthesis impossible.

To further support the notion that limited $\mathrm{PGI}_{2}$ synthesis is due to PGHS-1 autoinactivation in this infected cell line, we treated the cell repeatedly with $\mathrm{AA}(10 \mu \mathrm{M})$ at hourly intervals. At the end of each hourly stimulation, medium was collected and the 6-keto-PGF ${ }_{1 \alpha}$ content was measured. In five experiments, the 6-keto-PGF 1 $_{1 \alpha}$ content at the end of the first hour treatment was $365.5 \pm 40.5 \mathrm{ng} / 10^{6}$ cells which declined to $85.5 \pm 12.5 \mathrm{ng} / 10^{6}$ cells after the second AA challenge $(\mathrm{a}>75 \%$ decline) and $39.5 \pm 9.0 \mathrm{ng} / 10^{6}$ cells after the third AA challenge. These results confirm that PGHS-1 inactivates rapidly during catalysis and that $\mathbf{P G I}_{2}$ synthesis is still severely curtailed even in the presence of a large quantity of PGHS- 1 .

\section{Discussion}

Prostacyclin production is regulated at each of three enzymatic steps that catalyze its biosynthesis. Phospholipase $A_{2}$ is considered to be the limiting step for the initial rate of prostanoid synthesis, while PGHS is thought to control the extent of prostanoid production due to its suicidal inactivation during catalysis $(4,5,31)$. Prostacyclin synthase also undergoes autoinactivation but its role in controlling $\mathrm{PGI}_{2}$ synthesis generally is less clear. Despite extensive investigations, prostanoid synthetic rate in cells has been difficult to quantify because of low abundance of PGHS. In this study, we used retrovirus-mediated transfer of PGHS-1 cDNA to enhance the expression of this enzyme by $\sim 20$-fold over the basal level of enzyme expression. Unlike the use of plasmid vector for transient expression, the retrovirus-mediated transfer of PGHS- 1 cDNA into a physiologically relevant cell is stable and is unaltered by subculture of cells. This transduced cell line has been subcultured for more than 10 passages and the level of PGHS-1 expression as well as the capacity for $\mathrm{PGI}_{2}$ synthesis remains unchanged. Availability of this cell line enables us to reliably quantify $\mathrm{PGI}_{2}$ synthetic rate and $t_{1 / 2}$ of $\mathrm{PGI}_{2}$ synthesis. A short half-life of $\mathrm{PGI}_{2}$ synthesis (13.3 min) is due to autoinactivation of PGHS and PGI synthase. Relative contribution of each enzyme's inactivation to the short half-life of $\mathrm{PGI}_{2}$ production is unclear. Since PGHS-1 levels in this cell line are amplified by $\sim 20$-fold without a concurrent increase in PGI synthase levels, it may be speculated that limited $\mathrm{PGI}_{2}$ synthesis is due mostly to inactivation of PGHS-1. This notion is supported by the progressive decline of $\mathrm{PGI}_{2}$ synthesis by this cell line when it was repeatedly challenged with arachidonic acid. Despite a marked increase in PGHS- 1 levels by retrovirus-mediated transfer of PGHS-1 gene, the capacity of $\mathrm{PGI}_{2}$ synthesis was reduced by $75 \%$ after a single AA treatment and declined at a similar rate after each subsequent AA challenge. We cannot rule out the possibility, however, that PGHS and PGI synthase may be autoinactivated at a similar rate by a similar enzyme inactivation mechanism.

Although it is generally accepted that the extent of prostanoid synthesis is controlled by PGHS, this has not been directly documented. This study provides direct evidence to support the notion that the extent of $\mathrm{PGI}_{2}$ can be greatly enhanced by increasing the level of PGHS-1 in the cells. We found that PGI production in response to physiological agonists was greatly enhanced by the transduced cell line. This is of considerable therapeutic implications. Since $\mathbf{P G I}_{2}$ is a major defense molecule protecting the vascular wall against thrombosis, loss of $\mathrm{PGI}_{2}$-producing cells due to denudation of vascular endothelium has been considered as a major factor for uncontrolled thrombus formation that is responsible for acute coronary and cerebral arterial occlusion. Virus-mediated (retrovirus or adenovirus) transfer of PGHS gene represents a powerful strategy for restoring this defense mechanism in damaged vessel wall. In this cultured cell study, we clearly show that this strategy is feasible. Work is now in progress to determine the feasibility of transferring PGHS by retroviral or adenoviral vectors in vivo in animal models.

Analysis by HPLC of metabolites generated by the transduced cells revealed in addition to $\mathrm{PGI}_{2}$ a significant quantity of $\mathrm{PGE}_{2}$ and a small amount of 12-hydroxy-5,8,10-heptadecatrienoic acid (HHT). Since $\mathrm{PGE}_{2}$ and HHT are derived from $\mathrm{PGH}_{2}$, we interpret the results to indicate that overexpression of PGHS-1 leads to the synthesis of a large quantity of $\mathrm{PGH}_{2}$ which exceeds the capacity of PGI synthase and the excess $\mathrm{PGH}_{2}$ is converted to $\mathrm{PGE}_{2}$ and $\mathrm{HHT}$ by enzymatic and nonenzymatic mechanisms. The PGI synthase step, hence, represents the final bottleneck for controlling the synthesis of $\mathrm{PGI}_{2}$. To enhance $\mathrm{PGI}_{2}$ synthesis optimally at the vascular injury sites for defending against thrombus formation, enhanced expression of PGI synthase in conjunction with enhanced PGHS may be needed. The HPLC analysis also showed that the quantity of free AA in PGHS-1-enhanced cells was approximately equivalent to that in control cells despite a major difference in the AA metabolic activity between PGHS(R) and control cells. The reason for the release of a similar level of free AA irrespective to the state of AA metabolism is unclear (Fig. 4). It may be speculated that cells possess a mechanism for allowing the release of only a small amount of unmetabolized AA. It is interesting to note that the basal level of $\mathrm{PGI}_{2}$ production was at least an order of magnitude higher than the basal level produced by EA.926 cells or human umbilical vein endothelial cells. This implies that even at the quiescent state, phospholipases in this transduced cell line were highly activated, thereby releasing arachidonic acid which was converted to $\mathrm{PGI}_{2}$ via the PGHS pathway. The mechanism by which this occurs requires further investigation.

Little is known about the use of SV40 late promoter region for increasing mammalian gene expression. In this study, we demonstrate that it enhances PGHS-1 expression significantly and when compared to retroviral LTR promoter activity, its strength in enhancing PGHS- 1 mRNA is $~ 50 \%$ of LTR promoter activity. Two transcription start sites were identified in our construct. Ghosh et al. reported multiple potential transcription start sites in SV40 late promoter region (32). Sequence comparison indicates that the transcription sites in our construct are different from the potential sites reported by Ghosh et al. (32). This may be due to a deletion of $17 \mathrm{bp}$ in the sequence reported by Ghosh et al. (between nucleotide residues 95 and 96) when compared to the sequence reported in GenBank and reported by Fromm and Berg (33). When these missing base pairs are taken into consideration, the two transcription start sites noted in our study coincide with two major 
start sites reported by Ghosh et al. (32). These results indicate that the promoter activity is upstream from these two start sites. This cell line may be useful for further characterizing the SV40 late promoter activities.

\section{Acknowledgments}

The authors thank Dr. Ah-Lim Tsai for kinetic analysis, and Drs. Richard Kulmacz and David Loose-Mitchell for valuable advice. The excellent secretarial help from Ms. Teri Treviño is highly appreciated.

This work was supported by grants from the National Institutes of Health, U. S. Public Health Service (NS-23327 and HL-18584).

\section{References}

1. Smith, W. L., L. J. Marnett, and D. L. DeWitt. 1991. Prostaglandin and thromboxane biosynthesis. Pharmacol. Ther. 49:153-179.

2. Samuelsson, B., M. Goldyne, E. Granström, M. Hamber, S. Hammarström, and C. Malmsten. 1978. Prostaglandins and thromboxanes. Annu. Rev. Biochem. 47:997-1029.

3. Needleman, P., J. Turk, B. A. Jakschik, A. R. Morrison, and J. B. Lekowith 1986. Arachidonic acid metabolism. Annu. Rev. Biochem. 55:69-102.

4. Smith, W. L., and W. E. M. Lands. 1972. Oxygenation of polyunsaturated fatty acids during prostaglandin biosynthesis by sheep vesicle gland. Biochemistry. 11:3276-3285.

5. Egan, R. W., J. Paxton, and F. A. Kuehl, Jr. 1976. Mechanism for irreversible self-deactivation of prostaglandin synthase. J. Biol. Chem. 251:7325-7335.

6. DeWitt, D. L., and W. L. Smith. 1988. Primary structure of prostaglandin $\mathrm{G} / \mathrm{H}$ synthase from the sheep vesicular gland determined from the complementary DNA sequence. Proc. Natl. Acad. Sci. USA. 85:1412-1416.

7. Merlie, J. P., D. Fagan, J. Mudd, and P. Needleman. 1988. Isolation and characterization of the complementary DNA for sheep seminal vesicle prostaglandin endoperioxide synthase (cyclooxygenase). J. Biol. Chem. 263:3550-3553.

8. Yokoyama, C., T. Takai, and T. Tanabe. 1988. Primary structure of sheep prostaglandin endoperoxide synthase deduced from cDNA sequence. FEBS (Fed. Eur. Biochem. Soc.) Lett. 231:347-351.

9. Funk, C. D., L. B. Funk, M. E. Kennedy, A. S. Pong, and G. A. FitzGerald. 1991. Human platelet/erythroleukemia cell prostaglandin G/H synthase: cDNA cloning, expression, and gene chromosomal assignment. FASEB (Fed. Am. Soc Exp. Biol.) J. 5:2304-2312.

10. Wu, K. K., R. J. Kulmacz, L.-H. Wang, D. S. Loose-Mitchell, and A.-L. Tsai. 1992. Molecular biology of prostacyclin biosynthesis. G. Rubanyi and J. R. Vane, editors. Elsevier Science Publishers B. V., Amsterdam. 11-23.

11. Xie, W., J. G. Chipman, D. L. Robertson, R.-L. Erikson, and D. L. Simmons. 1991. Expression of a mitogen-repressive gene encoding prostaglandin synthase is regulated by mRNA splicing. Proc. Natl. Acad. Sci. USA. 88:26922696.

12. Kujubu, D. A., B. S. Fletcher, B. C. Varnum, R. W. Lim, and H. R. Herschman. 1991. TIS 10, a phorbol ester tumor promoter-inducible mRNA from Swiss 3T3 cells encodes a novel prostaglandin synthase homologue. J. Biol. Chem. 266:12866-12872.

13. O'Banion, M. K., V. D. Winn, and D. A. Young. 1992. cDNA cloning and functional activity of a glucocorticoid-regulated inflammatory cyclooxygenase. Proc. Natl. Acad. Sci. USA. 89:4888-4892.
14. DeWitt, D. L. 1991. Prostaglandin endoperoxide synthase: regulation of enzyme expression. Biochim. Biophys. Acta. 1083:121-134.

15. Wu, K. K., H. Hatzakis, S. S. Lo, D. C. Seong, S. K. Sanduja, and H. H. Tai. 1988. Stimulation of de novo synthesis of prostaglandin $\mathrm{G} / \mathrm{H}$ synthase in human endothelial cells by phorbol ester. J. Biol. Chem. 263:19043-19047.

16. Maier, J. A. M., T. Hla, and T. Maciag. 1990. Cyclooxygenase is an immediate early gene induced by interleukin-1 in human endothelial cells. $J$. Biol. Chem. 265:10805-10808.

17. Hla, T., and T. Maciag. 1991. Cyclooxygenase gene expression is downregulated by heparin-binding (acidic fibroblast) growth factor-1 in human endothelial cells. J. Biol. Chem. 266:24059-24063.

18. Price, J., D. Turner, and C. Cepko. 1987. Lineage analysis in the vertebrate nervous system by retrovirus-mediated gene transfer. Proc. Natl. Acad. Sci. USA. 84:156-160.

19. Yokoyama, C., and T. Tanabe. 1989. Cloning of human gene encoding prostaglandin endoperoxide synthase and primary structure of the enzyme. Biochem. Biophys. Res. Commun. 165:888-894.

20. Mann, R., R. C. Mulligan, and D. Baltimore. 1983. Construction of a retrovirus packaging mutant and its use to produce helper-free defective retrovirus. Cell. 33:153-159.

21. Edgell, C.-J.-S., C. C. McDonald, and J. B. Graham. 1983. Permanent cell line expressing human factor VIII-related antigen established by hybridization. Proc. Natl. Acad. Sci. USA. 80:3734-3737.

22. Suggs, J. E., M. C. Madden, M. Fredman, and C.-J.-S. Edgell. 1986. Prostacyclin expression by a continuous human cell line derived from vascular endothelium. Blood. 68:825-829.

23. Wu, K. K., R. Sanduja, A.-L. Tsai, B. Ferhanoglu, and D. S. Loose-Mitchell. 1991. Aspirin inhibits interleukin 1-induced prostaglandin $\mathbf{H}$ synthase expression in cultured endothelial cells. Proc. Natl. Acad. Sci. USA. 88:2384-2387.

24. Wang, A. M., M. V. Doyle, and D. F. Mark. 1989. Quantitation of mRNA by the polymerase chain reaction. Proc. Natl. Acad. Sci. USA. 86:9717-9721.

25. Gilliland, G., S. Perrin, K. Blanchard, and H. F. Bunn. 1990. Analysis of cytokine mRNA and DNA: detection and quantitation by competitive polymerase chain reaction. Proc. Natl. Acad. Sci. USA. 87:2725-2729.

26. Zyglewska, T., R. Sanduja, K. Ohashi, D. S. Loose-Mitchell, S. K. Sanduja, and K. K. Wu. 1992. Inhibition of endothelial cell prostacyclin H synthase gene expression by naproxen. Biochim. Biophys. Acta. 1131:78-82.

27. Sambrook, J., E. F. Fritsch, and T. Maniatis. 1989. Mapping of RNA with ribonuclease and radiolabeled RNA probes. Cold Spring Harbor Laboratory, Cold Spring Harbor, NY. 7.71-7.84.

28. Wu, K. K., A. C. Papp, C. E. Manner, and E. R. Hall. 1987. Interaction between lymphocytes and platelets in the synthesis of prostacyclin. J. Clin. Invest. 79:1601-1606.

29. Eling, T., B. Tainer, A. Ally, and R. Warnock. 1983. Separation of arachidonic acid metabolites by high pressure liquid chromatography. In Methods in Enzymology. W. E. M. Lands and W. L. Smith, editors. Academic Press, Inc., San Diego, CA. 511-517.

30. Sanduja, S. K., K. Mehta, X.-M. Xu, S.-M. Hsu, R. Sanduja, and K. K. Wu. 1991. Differentiation-associated expression of prostaglandin $\mathrm{H}$ and thromboxane A synthase in monocytoid leukemia cell lines. Blood. 78:3178-3185.

31. Lapetina, E. G., and P. Cuatrecasas. 1979. Rapid inactivation of cyclooxygenase activation after stimulation of intact platelets. Proc. Natl. Acad. Sci. USA 76:121-125.

32. Ghosh, P., V. B., Reddy, J. Swinescor, P. Labowitz, and S. M. Weissman. 1978. Heterogeneity and 5'-terminal structures of the late RNAs of Simian virus 40. J. Mol. Biol. 126:813-846.

33. Fromm, M., and P. Berg. 1982. Deletion mapping of DNA regions required for SV40 early promoter function in vivo. J. Mol. Appl. Genet. 1:457-481. 